\title{
MISTRAL MISTRAL
}

Journal of Latin American Women's

Intellectual \& Cultural History

\section{A través de la pantalla: Infancias queer en la literatura argentina del nuevo milenio}

\author{
María José Punte, Universidad de Buenos Aires / Universidad Católica Argentina
}

To cite this article: María José Punte. 2021. "A través de la pantalla: Infancias queer en la literatura argentina del nuevo milenio." Mistral: Journal of Latin American Women's Intellectual \& Cultural History 1 (2): 35-48, https://doi.org/10.21827/mistral.2.38027

\begin{abstract}
Childhood is taken up time and again in Argentine literature of the first decades of the $21^{\text {st }}$ century. These are novels that engage various forms of humor, from extreme satire to imposed naivety. This broad register serves to destabilize ideas established throughout the $20^{\text {th }}$ century about the management of the lives of minors. Imaginaries formed by television have become part of several texts, together with what could be termed the "infant library", that is to say, the children's literature read by contemporary writers. Argentine narrative of the period accounts for the serious social crisis caused by the hegemony of neoliberalism, as well as its consequences on children's lives, revealing the fissures in the discourses surrounding their rights. The present article examines these issues in relation to three recent novels: Quedate conmigo (2017) by I. Acevedo, La maldición de Jacinta Pichimahuida (2007) by Lucía Puenzo and Osos (2010) by Diego Vecchio. They will be addressed here within the theoretical frameworks offered by Kathryn B. Stockton in her book The Queer Child (2009).
\end{abstract}

Key Words: Childhood; Argentine literature; Queer theory; Television; Childhood readings

Resumen: La infancia es retomada por la literatura escrita en Argentina durante las primeras décadas del siglo XXI en novelas que apuestan a diversas formas del humor. Desde la sátira extrema hasta una ingenuidad impostada, aparece un registro amplio que sirve para desestabilizar ideas fijadas a lo largo del siglo XX en lo relacionado con la administración de la vida de los menores de edad. Los imaginarios televisivos entran a formar parte de los textos fundiéndose con la "biblioteca infante", es decir, con las lecturas que acompañaron las infancias de los y las escritoras contemporáneos. La narrativa argentina del período también da cuenta de la grave crisis social producida por la hegemonía del neoliberalismo, así como sus consecuencias en las vidas de las infancias, lo que tendió a mostrar las fisuras de los discursos en torno a sus derechos. Estas discusiones quedan registradas en las tres novelas - Quedate conmigo (2017) de I. Acevedo, La maldición de Jacinta Pichimahuida (2007) de Lucía Puenzo, Osos (2010) de Diego Vecchio-que serán abordadas aquí desde los marcos teóricos ofrecidos por la teoría queer, en particular por la propuesta de Kathryn B. Stockton.

Palabras clave: Infancia; Literatura argentina; Teoría queer; Televisión; Biblioteca infante 


\title{
A través de la pantalla: \\ Infancias queer en la literatura argentina del nuevo milenio
}

\author{
María José Punte, Universidad de Buenos Aires / Universidad Católica Argentina
}

\section{Espectros de infancia}

Se ha convertido en un lugar común la opinión de que las y los infantes contemporáneos van lentamente dejando a un lado los libros para ser absorbidos cada vez más por las pantallas, en especial, las de formato hogareño, sea bajo la forma del televisor o de los dispositivos digitales, entre las cuales va quedando incluso más marginada la visita a la sala de cine. Eso aparece reflejado en el deslizamiento de los imaginarios de infancia hacia los contenidos televisivos en las obras de las últimas generaciones de escritoras y escritores. Esta migración nunca abandonó por completo lo que podría ser definido como una "biblioteca infante", y que funciona como un corpus más o menos latente en numerosos proyectos narrativos. Latente, porque supone un sustrato más difícil de visibilizar o de reconocer como la matriz de todo relato que atraviesa la tarea de escritura (lo cual incluye la decisión de un devenir-escritor/a, así como las intertextualidades menos evidentes). En la literatura argentina, sin embargo, la carta de ciudadanía ya había sido adquirida a través del antecedente indudable que asentó Manuel Puig, quien abrió las grandes puertas al cine para la narrativa de ficción, el cine que él veneraba, el de las salas que calcaban los palacios hechos para soñar y fantasear sin límite. El paso siguiente, hacia la televisión, quedó canonizado por la obra de César Aira, con sus dinámicas que emulan el zapping, la variedad y la cantidad de contenidos, así como el carácter de "vale todo" que ha sido la marca registrada de la televisión desde sus comienzos. ${ }^{1}$ Ambos escritores son los precursores ineludibles de las narraciones que serán abordadas en las siguientes páginas, en las que se inspeccionan los vínculos entre los imaginarios de la niñez y las problemáticas que definen las infancias contemporáneas, desde la perspectiva de tres autores cuyos textos optan por el recurso de "queerizar" dichos imaginarios mediante el procedimiento de la hibridización textual que contribuye a "torcer" una imagen idealizada de infancia. Las tres novelas que serán comentadas a continuación comparten una experiencia que se inserta en el dormitorio infantil, espacio en mayor o menor medida burgués, cuyo escenario ofrece algo así como un marco provisorio: si bien hace un corte en el campo visual, también es lo que define el espacio de aquello que se desborda y funciona como el fuera de campo. A su vez, la evocación del aparato televisivo de nuestras infancias aquel que aparecía coronado por sus perillas y por una antena cibernética-, tiñe de una cierta pátina vintage a estas narraciones.

Los tres textos, a su vez, refuerzan la idea de que la infancia no es algo que queda en el origen, a lo que se retorna de manera fantasmática, sino que sigue formando parte de una red significativa que habla en un constante presente como a través de un

\footnotetext{
${ }^{1}$ Los cruces entre literatura y las diversas tecnologías comunicacionales, se fue dando de manera gradual pero constante desde el surgimiento del fonógrafo hasta el presente de la red, nos dice Norma Carricaburo (2008). En la literatura argentina, se puede seguir una clara genealogía que tiene como dos de sus figuras más destacadas a los mencionados Manuel Puig y César Aira. En cuanto a la televisión, los elementos que incorporan las y los autores hoy en día son la oralidad, las resoluciones técnicas audiovisuales, la diversidad temática, la pérdida de verosimilitud, la frontera débil entre realidad y ficción, la pluralidad de códigos.
} 
parlante, en un continuum que -además- se mueve con fluidez desde la literatura a la cultura audiovisual. Responde a lo que plantean René Schérer y Guy Hocquenghem cuando dicen que "No hay que partir del niño, del lugar vacío que ocupa, sino de la red, de la constelación en que este se sitúa" $(1979,52)$. Tanto en las obras de Acevedo, como en las de Puenzo y Vecchio, la infancia es una persistencia que imprime un sello indeleble en sus estéticas, por distintas razones y a partir de proyectos narrativos que son diversos entre sí. La infancia está como aquello que Cynthia Francica extraía de su análisis sobre lo "queer infantil" (que ella aplicaba a las obras de Fernanda Laguna y Pablo Pérez), ${ }^{2}$ pero que evidentemente atraviesa a un número considerable de escritoras y escritores que publican en el contexto de la crisis del 2001 (Francica 2015). Esa "fina línea que separa lo naïve de la ironía, la boludez ${ }^{3}$ de la parodia, la inocencia infantil de la perversión" $(2015,157)$, en palabras de Francica, dibuja la frontera exacta que ofrece contorno a las historias en las tres novelas elegidas para armar serie en torno a la tríada "infancia, televisión y literatura": Quedate conmigo (2017), La maldición de Jacinta Pichimahuida (2007) y Osos (2010). En las tres, de estos cruces que hacen referencia a los modos en los que las ficciones se entrelazan con las formas de situarse en el mundo, emerge una figura de infante que es queer, en los términos propuestos por la crítica Katrhyn B. Stockton. "Scratch a child, you will find a queer" $(2004,278)$, afirma esta autora, porque la torcedura (o el desvío) es el trazo que funda y define la infancia en sí. ${ }^{4}$ En las lecturas de las novelas que haremos a continuación, aparecerán algunas de las figuras entrevistas por Stockton y que atraviesan los actuales paisajes de infancia, en su carácter espectral: la díada que arman la niña y su perro; el infante agresivo y su contracara, el inocente; el niño fantasmal gay; el infante hecho queer por el dinero y por la cuestión de clase. En estas configuraciones, así como en los ejemplos a los que las novelas dan cuerpo con sus posibles variantes, se trata siempre de ver cómo las infancias intentan escaparse de los marcos normativos con las que el universo adulto se esfuerza por encasillarlas, por ponerlo "bajo custodia" (Shérer y Hocquenghem, 1979, 64). Como sabemos, esos esfuerzos que resultan bastante eficientes en los mundos reales, se tornan vanos cuando se da permiso a las ficciones de hacer su aporte desestabilizador, como se verá en los usos de los imaginarios infantes, objetos de rutilantes metamorfosis textuales.

\footnotetext{
${ }^{2}$ Lo queer y lo infantil son instancias que están imbricadas en estas obras que analiza Francica, y que constituyen una "intervención crítica clave" en la literatura de estos autores. Los dos estados de lo ingenuo y de lo queer, que suelen ser calificados como improductivos, tanto desde lo estético como de lo intelectual, suponen una táctica para indagar en un terreno que es político, algo que se hace evidente ante la falta de salidas en la crisis social y económica del 2001. Hay elementos lúdicos en ellas, vinculados a otra manera de pensar la circulación de las obras en los circuitos comerciales, así como de trabajar por afuera de la noción de canon (un gesto, además, feminista). La infantilización programada incluye al lector, al que se invita a participar del juego.

${ }^{3}$ La "boludez", ese término tan definitorio de lo argentino, puede ser equiparado con lo que plantea Seth Lerer cuando habla de las infancias contemporáneas y del formato humorístico que adoptan sus relatos, que parecen tener conciencia de la ironía y de ese "estar de vuelta de todo", de la distancia de lo que se dice y lo real. Lerer se refiere a eso a partir de la expresión "bullshit", que puede ser traducido al español rioplatense como la forma verbal "boludear", en su acepción de contar cosas que no son ciertas o de inventar. Implica un desapego de la experiencia que es consciente tanto del artificio como del rol de la imaginación. Afirma Lerer: "Bullshit is the artistic fiction of our age" $(2008,316)$.

${ }^{4}$ Para una introducción explicativa de lo que Kathryn B. Stockton desarrolla en su libro The Queer Child (2009), me remito a la introducción de este dossier.
} 


\section{Invasión extraterrestre}

"Es odiosa esta historia granulada día a día. Ojalá nadie la lea nunca jamás" Quedate conmigo

Para ser una historia originada en sentimientos opuestos y de una pasión excluyente, como son el amor y el odio, la novela Quedate conmigo (2017) de I. Acevedo avanza sin dificultades por la senda de lo narrativo. ${ }^{5} \mathrm{La}$ infancia alimenta el relato con una forma de facilidad como para que los hechos narrados adquieran verosimilitud, a pesar de su arraigo indudable en la fantasía. ${ }^{6}$ No solo porque las y los protagonistas de la novela son infantes (de entre diez y doce años), sino porque todo lo que sucede está contaminado por imaginarios de una niñez tramada por la televisión y por lecturas provenientes de la biblioteca infantil. Citados de manera explícita aparecen el personaje de Nancy Drew o las novelas de El club de los Cinco, junto con La guerra de los mundos y Farenheit 451..$^{7}$ Cualquier lector o lectora actual podría pensar que Quedate conmigo se escapó del estante de la literatura infantil-juvenil, si no fuera por ciertas torsiones que remiten a un humor que oscila entre lo satírico y una ingenuidad claramente impostada. ${ }^{8}$ El título, por su parte, evoca el de un programa televisivo de entretenimientos emitido entre 1991 y 1994 por la televisión argentina, Jugate conmigo, cuyos protagonistas era adolescentes y que conjugaba música, juegos, coreografías y actuación. La trama narrativa de la novela de Acevedo, sin embargo, se encuentra bien alejada del glamour de los sets televisivos. Transcurre en una localidad rural y sus protagonistas viven una existencia más cercana a las carencias y la vida estoica del campo que a las luces de la ciudad.

La narradora y protagonista del texto es Tati (Tatiana Ruppel) de diez años, quien junto a su hermana Loli y cuatro amigos más (Evangelina, Silvina, Ramiro y Nacho) viven la increíble aventura de un encuentro con visitantes provenientes del espacio exterior. La imagen que Tati misma compone de este grupo y del ambiente en el que desea insertarlo, se inspira en los libros infantiles, pero también en un cruce con el lenguaje de la publicidad (en su referencia a la marca de cigarrillos Marlboro), y da una pauta del tono general de todo el relato, así como de las transmutaciones que permite la ficción:

Imaginé un póster que era una mezcla de Nancy Drew y El club de los Cinco y el fondo era un paisaje Marlboro. Yo era la líder. Estaba un poco por delante con

\footnotetext{
${ }^{5}$ I. Acevedo (Tandil, 1982), nacida como Inés Acevedo, se presenta en la actualidad como un escritor, licenciado de la carrera de Letras por la Universidad de Buenos Aires, codirector de la editorial digital La Colección. Publicó las novelas Una idea genial (2010), Panadera (2015), Quedate conmigo (2017), y relatos breves en antologías, así como en los volúmenes Trilogía canina (2013), Jajaja (2017), Late un corazón (2019). Su transición de género sexual se produce en el 2018 y nombrarse con la "I" sostiene- implica definirse a partir de la idea misma de mutación.

${ }^{6}$ Algunos elementos que confluyen en la trama narrativa aparecían ya en un texto anterior, Una idea genial (2010), que es presentada por Acevedo como una forma de relato autobiográfico, en el que se ponen en juego elementos que remiten a un uso paródico del género. En cierto modo, se puede pensar a ambos textos como un relato de asunción del rol de escritor/a abordados primero desde lo biográfico y luego desde la ficción, y que exhiben la premisa compartida de la mutua contaminación.

${ }^{7}$ En una entrevista Acevedo menciona como intertextos "todas las novelas de Stephen King", como sucede con la película Cuenta conmigo (Rob Reiner, 1986). Subraya que pensó su novela como un texto de ciencia ficción. Véase Hadad, 2017. En cuanto al proceso de escritura y publicación del texto, está narrado en "Nadie quiere a los extraterrestres", relato que abre Jajaja (2017, 9-21).

${ }^{8}$ Sucede algo parecido con la novela de César Aira, Yo era una niña de siete años (2007), en donde aparece de tal manera fagocitado el género de literatura infantil que podría ser abordada como una incursión de Aira por el género. Algo que, por supuesto, es una parodia del sistema de géneros literarios.
} 
gesto decidido. Botas tejanas, camisa a cuadros y jeans, ya con un cuerpo adulto, se entiende. Llevaba una bandolera, y en ella un cuchillo de campo. A mi derecha, Nacho, a mi izquierda mi hermana, y atrás el resto (siendo las últimas en cada extremo Evangelina y Silvina, ligeramente de perfil y en un tamaño mucho más pequeño). Estábamos rodeados de un polvillo misterioso. Avanzábamos con decisión entre esa bruma, y no pararíamos hasta resolver el misterio. (61)

En una tesitura que se remite al filme E.T., el extraterrestre (Spielberg 1982) ellos son los únicos del pueblo involucrados con la llegada de los visitantes cuando entran en contacto con dos perros, Susi y Sulivan, que no son tales sino dos ciborgs con forma canina. El objeto ovoide que cae en el campo de la familia de Tati y que los adultos perciben como un meteorito, resulta ser una nave proveniente de la luna que llega a la tierra con una misión específica. Pero, mientras que los adultos no parecen tomar nota de los hechos extraños que se van sucediendo (la muerte del hermano de Tati succionado por la nave, el crecimiento desmedido de las plantas a causa de una supuesta influencia de la nave espacial), los chicos se embarcan con total naturalidad en esta aventura. La elección por parte de los marcianos de Tati como testigo privilegiado no parece ser casual, sino un elemento calculado del plan de los visitantes: la chica es considerada indispensable para completar un capítulo de Las mil Historias, una especie de cosmogonía universal que incluye a los terrícolas a causa de lo que supondría el privilegio de poseer el lenguaje (Susi le explica que los extraterrestres no tienen lenguaje por culpa de la excesiva tecnificación).

La pareja protagonista de la novela son Tati y la perra Susi. La llegada de esta perra trilingüe, que puede leer la mente y que entiende muy bien los conflictos íntimos de la niña van a perturbar una existencia anodina desarrollada entre los campos de trigo y las arboledas de esa zona rural en el sur de la provincia de Buenos Aires (en la fértil región llamada "pampa húmeda"). ${ }^{9}$ Tati siente un acuciante deseo de adquirir algo de protagonismo, dada la posición intermedia e indefinida que tiene dentro del esquema familiar: no es la mayor, tampoco la menor. La edad por la que transita la ubica en una instancia en donde ya no necesita de tanta atención, pero todavía no puede jugar en otras ligas mayores. Por ejemplo, se queja de que nadie le paga por las tareas que realiza en la casa, a diferencia de su hermana Loli. Todo parece colocarla en un espacio de indeterminación que la enerva y le produce ese "odio" que declara al comienzo de la novela: "¿Qué es el odio? Seguro que es algo muy feo, pero si no hubiera sido por el odio, nada de esto habría pasado. En esa época yo sentía odio. Y si me preguntan por qué, lo sabía: odiaba ser niña, odiaba ser mujer. Odiaba ser gorda y odiaba usar anteojos" (10). La llegada de la perra Susi produce un cambio copernicano en su existencia y la arroja a un periplo al que Tati por momentos parece oponer resistencia. Al fin y al cabo, como ella misma declara, "Detestaba que las cosas se salieran de la rutina" (10). Pero ni la perra Susi, ni los hechos que se irán encadenando a instancia de los otros dos "marcianos" -el mencionado perro Sulivan y el androide Leo Scarpa-, van a permitir que ella se evada de la tarea de "contar la historia y narrar el mundo" (41).

En principio, el personaje de Tati no tiene ningún rasgo extraordinario que justifique el asedio de los visitantes provenientes del espacio exterior. Es una chica

\footnotetext{
${ }^{9}$ La novela se hace eco de las transformaciones que fue sufriendo el campo en la Argentina a partir de la década de los noventa, con dinámicas de despoblamiento y tecnificación, así como de avance de una forma de explotación intensiva y más orientada a sacar un rédito inmediato que a respetar el ecosistema. En ese sentido, es que han ido cambiando los imaginarios literarios sobre este espacio tan representativo de la construcción de lo nacional en el país. Para el tema de estos cambios, que en la literatura vienen de la mano de nuevas configuraciones en torno al género sexual, véase De Leone (2020).
} 
común, con un interés por la lectura usual para su edad, que tal vez resulte llamativo en ese ámbito rural y que da pie para pensar el texto mismo como producto de una fabulación alimentada por los libros. La figura que se arma con la presencia de la perra Susi, no obstante, hace que el personaje adquiera otras derivas como las que analiza Katrhyn B. Stockton en su libro The Queer Child (2009), y a las que denomina el "intervalo animal". La presencia de los animales, pero particularmente de los perros, genera en los textos algunas de las relaciones laterales que Stockton concibe como aquellas que producen los movimientos no lineales que torsionan la figura del infante queer; esos crecimientos de los sujetos infantes hacia los costados que desmienten la idea de un desarrollo unívoco, lineal y cronológicamente diseñado.

Stockton vincula la presencia del perro específicamente con la figura de la niña lesbiana. ${ }^{10} \mathrm{El}$ animal le permite al infante un espacio de juego que acentúa la demora y sus movimientos internos, por lo tanto, una temporalidad alternativa al mero crecimiento en dirección hacia la adultez. A su vez, le propone un modo de reconfiguración de la estructura familiar al ofrecerse como metáfora viviente de la familia y objeto de sus atenciones. El perro es vehículo del extrañamiento del infante, en este caso, de la niña. Con respecto a la lesbiana, la relación con el perro constituye una forma de investimento libidinal, a la vez que triangula un vínculo impronunciable, aunque evidente. ${ }^{11}$ En la novela de Acevedo, la presencia de la perra Susi funciona como el planteo de Stockton de que el animal es la pantalla viviente sobre la que se producen las auto-proyecciones de los infantes y, en ese sentido, los acompaña en su queerness. Susi, la perra de flequillo platinado y largas pestañas, es la amiga ideal; una especie de hada madrina que le cumple a Tati sus deseos (la blusa escocesa "perfecta") y le cura literalmente las heridas -“¡Exactamente igual que en E.T.!” (18)-. La historia de Susi no parece extrañar a Tati, quien la acepta sin dilación: Susi viene de la Luna, que es un lugar para construir y entrenar perros androides; estos perros van alcanzando diferentes niveles de desarrollo y son creados para autodestruirse (como los ciborgs de la película Blade Runner). Su misión es realizar tareas de cuidado. A diferencia de su compañero Sulivan, Susi tiende a ser siempre una presencia benéfica para Tati y sus amigos. Constituye para la niña una forma añorada de familia que le sirve de compensación a lo que ella vive como una serie de carencias, tanto materiales como afectivas.

La novela de Acevedo produce un giro significativo en el tratamiento del tópico de los extraterrestres, al correrlos del lugar de "invasores" para retomar otras líneas narrativas que tienden a considerarlos desde una perspectiva más benévola, más allá de que las intenciones del androide Leo siempre tienden a resultar aviesas y de que el personaje del perro macho Sulivan suele tener conductas más agresivas que su partenaire Susi. ${ }^{12}$ Lo extraño interviene en lo cotidiano produciendo una forma de

\footnotetext{
${ }^{10}$ Stockton analiza para esto escenas de Mrs. Dalloway (1925) de Virginia Woolf, The Well of Loneliness (1928) de Radclyffe Hall, y Nightwood (1936) de Djuna Barnes. Pero también abordará el ejemplo de la novela Lolita (1955) de Nabokov y de sus versiones fílmicas, en las que se conjuga la noción de niño sexuado, en tanto que infante ficcional, con la metáfora de los movimientos propuesta a partir del lazo entre esta niña y su perro, al que Stockton define como una "máquina del tiempo" porque desdibuja la cronografía. Lo primero aparece en el capítulo 2 (89-116) y lo segundo en el capítulo 3 (119-153).

${ }^{11}$ Esto parecería ser parodiado en el relato del Génesis narrado por Susi, en donde la presencia del perro se inserta en lo que sería una pareja originaria formada por dos niños, Zulma y Alexis. La narradora (Tati) hace notar que lo interesante de este relato narrado por Susi, y que sería el primero de Las mil historias, es que la intención de contar la historia y de narrar el mundo suele verse deformada por las cosas que efectivamente ocurren en el mundo, como se ve en este caso con la aparición del perro (41).

${ }^{12}$ En la literatura argentina de la generación previa, la "invasión extraterrestre" había quedado asimilada a la serie televisiva de los años sesenta Los invasores, a partir de una lectura política que apuntaba a lo
} 
contaminación que, por otro lado, es la marca registrada del mundo contemporáneo. Quedate conmigo apuesta por el humor y por cierta ligereza que se piensa desde los imaginarios de infancia, lo que incluye todo lo visto en la televisión durante largas tardes de sábado, sean películas o series. De yapa, deja latiendo esa impresión que transmiten niñas y niños de que todo es posible y de que el mundo está aún por hacerse.

\title{
Niños prodigio
}

\author{
"Crecer es dejar de ser una promesa" \\ La maldición de Jacinta Pichimahuida
}

En su libro Infancias argentinas (2019), Mirta Zaida Lobato dedica una mención a los niños y las niñas artistas dentro del capítulo dedicado al trabajo infantil. Hace la salvedad de que la participación de menores en las labores artísticas suele ser un campo "bastante desconocido". Las actividades relacionadas con este rubro parecen quedar vinculadas con las "vocaciones". Pero, así como era frecuente que hubiera infantes tanto en las compañías circenses como teatrales, también fue moneda corriente la presencia de niños y niñas actuando en la radio, en el cine o en la televisión: "Aunque tenían jornadas de aprendizajes y de entrenamientos, cumplían horario y recibían remuneraciones, el trabajo artístico (actoral o musical) no era considerado trabajo" (105). Lucía Puenzo aborda el tema de la actuación infantil de manera intensamente satírica en su novela La maldición de Jacinta Pichimahuida (2007), cargando las tintas sobre la cuestión del éxito fugaz y el posterior olvido de los actores precoces, así como de las secuelas psicológicas que esto produce. ${ }^{13}$

El texto hace referencia a un programa televisivo muy popular que tenía como protagonistas a una maestra del nivel primario de una Escuela Nacional en Buenos Aires, Jacinta Pichimahuida. Era el centro de una constelación que incluía a sus alumnos, entre quienes se destacaban algunos personajes que portaban rasgos distintivos mediante los que se intentaba representar la variedad de clases que albergaba la escuela pública. ${ }^{14} \mathrm{El}$ creador de la saga, que contó con cuatro ediciones de acuerdo con las actrices que interpretaron el rol de la maestra desde sus inicios en el año 1966

siniestro (en el sentido de lo Umheimlich) con connotaciones claramente negativas y mediante la que se metaforizaba la violencia de la última dictadura argentina. Así es como aparecía en las novelas Kamchatka (2003) de Marcelo Figueras e Historia del llanto (2007) de Alan Pauls. También era retomado de esa manera por la autora chilena Nona Fernández Silanes en su novela Space Invaders (2014) para leer la dictadura en Chile. Un antecedente insoslayable era el que proponía la historieta $E l$ Eternauta de H.G. Oesterheld, precursora para el caso argentino. Una crónica muy ilustrativa del cine con tema "marcianos" es la que ofrece José Pablo Feinmann quien, con mucho humor y amor por el cine, nos lleva a un paseo por las diversas épocas del género. Concluye con una reflexión filosófica: los filmes de marcianos contienen en sí una de las grandes cuestiones que nos plantea la condición humana que es la de no desearnos solos en el universo (Feinmann 2000, 31), un elemento que está presente en el texto de Acevedo.

${ }^{13}$ Lucía Puenzo nació en Buenos Aires en 1976. Egresada de la Escuela Nacional de Experimentación y Realización Cinematográfica (ENERC) y estudió Letras en la Universidad de Buenos Aires. Su obra se compone tanto de producciones audiovisuales (tres largometrajes, cortos, series para televisión), como de guiones, e incluye hasta la fecha las novelas El niño pez (2004), 9 Minutos (2005), La furia de la langosta (2010), La maldición de Jacinta Pichimahuida (2007), Wakolda (2011), Los invisibles (2018) y los relatos de En el hotel cápsula (2017).

${ }^{14}$ En paralelo a este programa televisivo, pero como una versión "intelectualizada" y de una calidad artística indudablemente superior, Quino (Joaquín Salvador Lavado) realizó la tira cómica que tenía como protagonista a una niña de la escuela primaria, su ya inmortal Mafalda, y a sus amiguitos. La historieta se publica entre 1964 y 1973. Para un análisis pormenorizado de su historia, véase Cosse (2014). 
hasta su conclusión definitiva en 1985, fue el guionista Abel Santa Cruz (1911-1995). ${ }^{15}$ La novela de Puenzo sigue las andanzas de uno de sus supuestos actores a lo largo de dos líneas narrativas: una que sucede en el presente del año 1995 cuando el protagonista, Pepino (el sobrenombre que recibe a partir de la serie televisiva), tiene treinta años, ${ }^{16}$ otra que se retrotrae a la época en la que tuvo lugar la filmación del programa, cuando Pepino contaba con nueve años, es decir, en 1975. La mencionada "maldición" se hace eco de las leyendas urbanas generadas en torno a la pequeña troupe actoral, al poner el acento en los supuestos fracasos y las frustraciones originadas en ese éxito inicial que no tendió a concluir con las rutilantes carreras esperadas. Si bien este es un fenómeno usual de la actuación infantil, en la novela es utilizado como metáfora de una situación social y política que no se vincula solo con el espacio televisivo, sino con todos los ámbitos laborales del país y con las falsas promesas del sistema neoliberal transnacional que se afianza en la década de los noventa. Este paralelo se hace explícito en la novela, como sostiene su protagonista, Pepino: "Es perfecto, pensó Pepino. El maestro alcanzaba su obra maestra: veinte años después de encarnar la esperanza de un futuro mejor volvían al centro de la atención pública en una cadena de tragedias. Mientras el país se derrumbaba los protagonistas de Señorita maestra morían" (214, cursivas en el original).

El carácter circense del rubro actoral se ve subrayado por cierta mirada anamórfica que la narración echa sobre estos personajes: son como los "freaks" inmortalizados por la película homónima de 1932 de Todd Browning. Los rasgos extremos de los personajes los sitúan en el ámbito de lo monstruoso, de aquello que, al exceder las medidas ideales, se ubica en el terreno de lo "anormal". ${ }^{17}$ A su vez, los procedimientos de hibridación y de mezcla se trasladan a la palabra: la contaminación entre ficción y realidad es constante hasta el punto de que ya resulta imposible separar la una de la otra. No se trata solamente del desvarío de su protagonista, Pepino, que se ha quedado congelado como la peor versión de sí mismo. Treinta años más tarde, Pepino sigue convencido de que el "Maestro", Abel Santa Cruz, puede digitar la realidad a su antojo a partir de la escritura: "Se arrodilló frente a la cama y leyó la escena sin tocarla. Todo estaba ahí. Cada acción, cada palabra, como si la vida entera pudiera ser adivinada de antemano" (186, cursivas en el original). En ese sentido, la novela retoma la idea de la escritura como "misión" que es encomendada a los niños con la ilusión de que puedan ser agentes de su propia historia, aunque sea de manera vicaria. En sintonía con una fuerte crítica a los medios masivos de comunicación está circulando la premisa de que todo aquello que no aparece en la televisión o en las

\footnotetext{
${ }^{15}$ Las actrices que interpretaron a la maestra y que distinguieron cuatro etapas fueron Evangelina Salazar, Silvia Mores, María del Carmen Valenzuela y Cristina Lemercier, quien protagonizó el ciclo que llevaba por título Señorita maestra (1982-1985). En 1977 apareció una versión fílmica, Jacinta Pichimahuida se enamora, protagonizada por María de los Ángeles Medrano. Todas estas actrices corporizaron el estereotipo de la mujer angélica y maternal, sin fisuras ni ambigüedades.

161995 no solo es el año en el que muere el creador de la serie, Abel Santa Cruz, sino en que se suicida la última de sus protagonistas, Cristina Lemercier, que padecía una fuerte depresión ante la falta de trabajo. Este es uno de los hechos que aparece retomado en la trama narrativa sobre el cual se monta la idea de "maldición", junto con otros (la muerte dudosa de una de las niñas del elenco, un supuesto accidente que se cree que fue un suicidio; la carrera delictiva de otro de los niños que terminó preso).

${ }^{17}$ La cuestión de lo "anormal", en sus vínculos con lo monstruoso y la monstruosidad, es utilizado por Foucault para pensar el funcionamiento de la ley, de sus límites y contingencias, así como de los modos en que a través de esta son formateados los sujetos y organizados mediante jerarquías, destinados a espacios pertinentes y configurados a partir de discursividades específicas. Los infantes hacen serie con los criminales y los locos dentro de un sistema que apunta a lograr una mayor eficiencia en el control poblacional, pero que no parece tomar en cuenta los aspectos muchas veces irrisorios y grotescos a los que conducen estos discursos pretendidamente científicos (Foucault 2010).
} 
publicaciones periódicas, carece de entidad real: no existe. De ahí la desesperación del personaje central por ser reconocido como uno más del grupo de niños y niñas que conformaron el elenco del programa.

La sátira esperable que permite una historia narrada desde las bambalinas de un set televisivo no ahorra detalles escabrosos acerca de la manipulación a la que son sometidos los menores de edad, especialmente por parte de sus progenitores. La magia del estrellato se desvanece desde el momento mismo en que comienzan las tareas de filmación; los estados de angustia y de stress, la competencia brutal y la pérdida de cualquier posible derecho de la infancia a la protección y al bienestar, pasan a mejor vida para los pequeños actores. Es decir, comienzan a experimentar la entrada a la vida laboral como una forma de tortura psíquica, más allá de la adulación y la devoción que producen en todos aquellos que, como Twiggy, solo pueden contemplar desde la distancia las delicias de la fama, a la que más tarde podrá acceder por la puerta lateral de la industria del porno. Una de las formas de la "queerización" de la infancia, entonces, se muestra en la novela de Puenzo en lo que Kathryn B. Stockton describe en la tercera parte de su libro como aquella que se genera a causa del dinero (o de su falta). Entre otras cosas, Pepino descubre tras la búsqueda desenfrenada a la que lo lanza el reencuentro con los jirones de su historia pasada que "Había olvidado hasta qué punto el programa los había transformado en mercancía. Durante un año las caras de los protagonistas fueron chupadas y masticadas por millones de chicos" (235). Explotación laboral y mercantilización hablan a las claras de un sistema que insiste en devorar literal y figuradamente- a sus propios hijos. Pepino se vuelve queer porque desmiente un crecimiento lineal: es un espectro, alguien que ha quedado fijado en una condición "larval", oscilante entre la vida y la muerte. ${ }^{18}$ No alcanza la muerte literal como otros personajes de la tira, pero es consciente de su estado de no-vida: "Los nenes que fuimos fueron matados por los adultos que somos" (251). Se define como un amoral, alguien para quien se han borroneado por completo las demarcaciones de lo que es un actuar correcto o incorrecto. Sin embargo, no es el único ni una excepción a la regla: es el último en registrar dicha circunstancia. Esta figura infante que se encuentra en un "entre-medio" que oscila entre lo fantasmal y el desfasaje temporal (algo que Stockton piensa a partir de la noción freudiana de "desarrollo detenido"-arrested development), confronta como un espejo a los adultos y los obliga a verse a sí mismos en toda su miseria. ${ }^{19}$

\section{Elige tu propia aventura}

"Aquellos que duermen, aunque permanezcan en el mismo lugar, se alejan de quienes están despiertos"

Osos

La novela Osos (2010) de Diego Vecchio retoma mediante un humor entre ingenuo y corrosivo el recurso de una extrema parodización de los discursos vinculados con la

\footnotetext{
${ }^{18}$ Para un análisis más detallado de esta cuestión de la "larva", véase en Punte (2018) el capítulo dedicado a la novela, "La maldita infancia y el secreto de una traición gozosa" (69-82).

${ }^{19}$ Particularmente virulentas en la novela, son las confrontaciones entre Pepino y su madre, una especie de mantis religiosa, una de las madres más malvadas de la galería de Puenzo, descripta como si fuera una araña gigante o un dragón, siempre desmesurada y, por ende, monstruosa. La madre ejerce todo tipo de violencia sobre su hijo Pepino, desde su explotación como mercancía, la manipulación psicológica, hasta el abuso sexual.
} 
infancia que circulan en la actualidad. ${ }^{20}$ En ella son acentuadas las hibridizaciones entre los medios audiovisuales, como la televisión y el cine, y la biblioteca infante, en particular la referida a los cuentos de hadas y relatos tradicionales (Punte 2018, 167 y ss.). De manera más o menos travestida, el texto cita las películas de Disney y de Pixar (claramente, Monster Inc., una película de animación de 2001), ${ }^{21}$ junto con personajes que poblaron los imaginarios de las infancias de los años setenta como, por ejemplo, el Topo Gigio. Los cuentos de hadas, en particular "La bella durmiente", ofrecen una matriz de interpretación en la que son equiparados los mitos con el relato bíblico. ${ }^{22}$ Todo ese material tan diverso aparece fagocitado por la capacidad de engendrar narraciones ante la necesidad de dar una forma inteligible a la experiencia, así como de recolectar sus enseñanzas y de configurar comunidad (Zipes 2012). La versión del siglo XXI produce una mezcla en la que conviven la televisión y la literatura en pie de igualdad, mediante la que se cuelan los discursos científicos y técnicos. En la novela, la centralidad adjudicada a la infancia a propósito de esta convivencia espuria pone el acento en los discursos médicos, pedagógicos y psicológicos. En ese sentido, la novela ofrece una versión queer de las ideas que arman la constelación en torno a lo narrativo. Y dicha queerización recurre a lo infante, es decir, a una programada minorización de la temática.

En lo concerniente a las infancias, la idea central se sostiene en la capacidad desestabilizadora para el mundo adulto que constituye la presencia de niñas y niños. ${ }^{23}$ La novela abre con una madre al límite de la extenuación psíquica por la falta de sueño que le produce el insomnio de su hijo menor, Vladimir. El niño no puede dormir porque le falta su oso de peluche, Oklahoma. Abundan las explicaciones psicológicas a lo largo del texto que resuenan como los ecos de aquello que todo infante escucha decir por parte de los adultos que lo rodean, pero que le llega como un rumor más, uno que se entremezcla con todas las otras voces que recibe desde los medios audiovisuales y que, aún en sus versiones más edulcoradas, están puestas al servicio de la domesticación. Como afirma una de estas voces: "el niño le aplicará al oso todos los métodos que los mayores le aplicaron a él" (13). Esto queda subrayado, sobre todo, en el modo en que al niño se lo piensa animalizado en el texto: deberán dormir como un lirón (11) o como un cocodrilo (13); beben la sopa con sorbidos de oveja o lengüetazos de coyote (35). De hecho, la aventura que vivirá Vladimir desde el momento en que comienza su diálogo con Otto (la variante malvada del oso de peluche), lo lleva a un universo de animales como el de un dibujo animado, donde las heroínas son las ranas y la vida late

\footnotetext{
${ }^{20}$ Diego Vecchio (Buenos Aires, 1969) es narrador, ensayista y traductor. Entre sus publicaciones se cuentan Historia calamitatum (2000), Egocidios: Macedonio Fernández y la liquidación del Yo (2003), Microbios (2006), Osos (2010), La extinción de las especies (2017). Reside en Paris desde 1992 y trabaja en la Universidad Paris 8 Vincennes-Saint Denis, dando clases de literatura hispanoamericana y creación literaria. Invito aquí a les lectores a leer el texto que Diego Vecchio escribió especialmente para este dossier en donde narra las idas y vueltas en torno de su novela Osos.

${ }^{21}$ No parece nada casual que la película de animación Monster Inc. sea un objeto privilegiado de estudio del teórico Jack Halberstam, quien considera que tanto Pixar como la compañía Dream Work han creado un mundo animado rico en alegorías políticas, a partir de sus analogías entre lo humano y lo animal, pero también por la cantidad de elementos queer que pueden ser rastreados allí (2011, pos. 480).

${ }^{22}$ Francica analiza un tipo de fantasía queer que recurre a la lógica narrativa de los cuentos de hadas, en el uso de lo maravilloso y del encantamiento, como "marco y soporte de una experiencia sexual radical" (176), para pensar en otras formas de habitar el mundo y de sostener vínculos afectivos ni hetero- ni crononormativos $(2015,176$ y ss.).

${ }^{23}$ Este es el argumento sobre el cual hace hincapié Catalina Donoso en su libro sobre representaciones problemáticas de infancia con un corpus de obras provenientes especialmente del cine chileno. Como sintetiza Donoso, la infancia es una "fuerza que desarma y desarticula los andamios de la sociedad adulta, que la pone en jaque y la hace exhibir su trastienda" $(2020,59)$.
} 
bajo el formato de la fauna más variada. A eso se suma una lógica adulta que se ve puesta en entredicho por la lógica del infante, de carácter puramente lúdico.

En la novela el oso de peluche constituye, en primer lugar, una referencia explícita al concepto que el psicoanalista Donald W. Winnicot definió como "objeto transicional", un objeto material sobre el que el infante deposita cierto apego y que le sirve como sustituto de la figura materna. Se sirve de él para la constitución del yo en su vinculación con el mundo exterior y se encuentra relacionado con la situación de conciliar el sueño. Más allá de esta idea que funciona como pivote narrativo principal, y en una tesitura semejante a la de los cruces discursivos mencionados, el texto explota todas las posibles connotaciones que resuenan en torno de este juguete, compañía inseparable de la primera infancia. A su vez, el oso de peluche se torna fetiche, por lo que queda ligado a la sexualidad. Es lo que se sugiere mediante el epígrafe que cita a Andy Warhol quien, ante la pregunta de cuál fue la persona más excitante con la que estuvo en la cama, responde que su oso de peluche. ${ }^{24}$ Como se sabe, el "oso" es una figura del imaginario gay que corporiza a un hombre maduro de cuerpo fornido y peludo, con barba, masculino, y que se ofrece como alternativa a un estereotipo feminizado de varón. De ahí se abre una lectura metafórica en abismo que piensa la pérdida amorosa y el duelo a realizar, en el marco del rol que juegan las fantasías para la configuración de la vida psíquica. El relato de este oso que le habla al niño, y que se condensa sobre todo en la matriz narrativa de los mitos de origen, contiene el romance entre el creador de los osos para dormir, Chang Hwan, y el osezno que encuentra en el bosque. En el origen de todo, por lo tanto, hay una historia de amor: "Entonces se produjo entre aquel humano y aquel animal algo verdaderamente increíble, inefable, irrepetible, irrefrenable, envidiable, deleitable y arrebatador, que cambiaría para siempre el rumbo de sus vidas" (71). Esa historia, como otras que se irán sumando en la fantasía exploratoria de Vladimir, se asumen desde la disidencia sexoafectiva.

La situación que presenta la novela puede ser leída también desde la noción de rapto, tal y como la desarrollan René Schérer y Guy Hocquenghem en Co-ire Álbum sistemático de la infancia (1979), un texto nodal para pensar los cruces entre infancia y literatura desde el descentramiento que supone una mirada queer. Este libro, como se recordará, abre con una afirmación arriesgada y problemática, sobre todo si se piensa en el contexto europeo de los años setenta (pero que sigue siendo de compleja recepción): "El niño está hecho para ser raptado, de esto no cabe duda. Su pequeñez, su debilidad, su hermosura invitan a ello. Nadie lo duda, empezando por él mismo" (9). El rapto al que se refieren tiene que ver más bien con los mundos de aventuras y de ficción en los que parece quedar sumido el infante durante cierto periodo de tiempo, al que deberá renunciar si quiere vivir en el mundo de los adultos, y al que algunos sujetos -sobre todo los y las artistas- no parecen querer abandonar lo cual estaría funcionando como una marca de su diferencia (representado por lo que dio en llamarse mediante una metáfora tomada de la literatura el "síndrome de Peter Pan"). La fantasía del rapto que se cuela en numerosos textos literarios, que hicieron las delicias de nuestra infancia, genera identificaciones. Los autores constatan que ese rapto es tan temido como anhelado, porque responde a un deseo de quiebre de la seguridad cotidiana e irrupción

\footnotetext{
${ }^{24}$ Resulta sugerente que Stockton concluya su libro The Queer Child con una referencia a Andy Warhol, a quien presenta en las conclusiones como un personaje que reúne en sí varias de las características que fue desglosando en su análisis: es el gay fantasmal, hecho queer a través del color (la intensificación del blanco, en su caso), freudianamente fijado en la madre, vuelto luego el chico homosexual de la cultura y del arte norteamericanos de posguerra. Tal vez radique en una súplica de más y más que funciona como una copia creativa de América - "the original, creativ copy of America", sostiene Stockton-, que le devuelve su imagen en espejo, sobre todo en lo referido a su vínculo con el dinero $(2009,220)$.
} 
de lo extraño. Desde el punto de vista espacial, arma serie con la partida, el vagabundeo, la fuga, el viaje. En cuanto al vector temporal, rompe con la lentitud y parsimonia de la vida cotidiana que son la matriz de toda pedagogía (el lento trayecto educativo de maduración, crecimiento y vigilancia), ese "envolvente pensamiento parental" (11). El arrancamiento repentino e instantáneo produce desgarro a la par que liberación, y suele funcionar como un encuentro revelador. Por otro lado, advierten los autores, el niño constituye una prenda del mantenimiento del orden social. En la lógica de la ciudadanía ya funciona la idea de secuestro, pero invertida. El rapto estaría introduciendo un tercer término que altera esa lógica y hace emerger lo distinto. Es la puerta abierta a lo desconocido, lo monstruoso, lo inhumano.

En la novela se presenta, asimismo, la cuestión del dinero o de la monetarización, pero no en términos de conversión del infante en mercancía (como en el relato de Puenzo), sino con el acento colocado en la figura del "niño consumidor". Ya en el primer capítulo se despliega con una enorme carga satírica mediante la escena en la que la madre corre a comprar el oso publicitado para hacer dormir a los infantes. El lenguaje parodiado es el de la publicidad más craso, pero a lo largo del texto irá reapareciendo a través de los destellos que se dejan ver de la penetración televisiva en los imaginarios de los y las menores: todo programa de televisión viene acompañado de su merchandising, aún el más abiertamente pedagógico. Aquí estaría situada la imposibilidad de la inocencia en lo que se refiere a la niñez. En el caso de Osos, la queerización del infante se liga a la categoría que Stockton denomina como del "niño normativo" (30), la de aquel que debe ser protegido a toda costa de la supuesta corrupción del mundo adulto y que, como ella hace notar, suele ser representado como blanco y de clase media. La novela, por su parte, va cambiando la focalización desde la perspectiva de una madre obsesionada con el bienestar de su hijo, culpabilizada por la sociedad que impone los parámetros de lo que es ser una buena madre, al universo de Vladimir en el que conviven temores y fantasías, y que parece desentenderse de tanta preocupación para concentrarse en el reencuentro de lo único que vale la pena en la vida: su objeto de deseo, el oso.

\section{Conclusiones para una forma de conocimiento "indisciplinado"}

Las miradas que las tres novelas echan sobre las infancias contemporáneas pueden resultar más o menos descarnadas, más o menos realistas. Los imaginarios acuñados desde aquellas producciones que les estaban destinadas, así como de las diversas interpretaciones que se fueron gestando en torno suyo, traen restos de todas las construcciones históricamente sedimentadas y exhiben, como en una suerte de configuración geológica, diversas temporalidades que cristalizan en lo que hoy se entiende por "infancia". No resultan, por lo tanto, unívocas, sino que permiten desplegar una forma de mapa sobre un colectivo, el infante, que da cuenta de situaciones extremas en los modos de habitar este mundo y de la enorme polarización que caracteriza nuestro universo presente. En ese sentido, las infancias son como un parpadeo que emula la idea de síntoma (freudiano) o lo que Walter Benjamin reponía como "inconsciente óptico". Así es como desfilan niños y niñas ante nuestros ojos como en una calesita: los de a pie, los que vienen en auto; los travestidos, los animalizados, los infantilizados, los adultizados, los cosificados. Lo que queda claro es lo que sostenían Schérer y Hocquenghem en la idea de que nunca están donde se los busca, porque la definición misma de infancia radica en ese "ponerse fuera de alcance, de subvertir la lógica adulta mediante la rapidez de sus desplazamientos" (1979, 43). 
Como el zapping que permite hacer la televisión, las infancias no solo se mueven: son el movimiento mismo que no da respiro.

Se vuelve a los imaginarios de infancia no por nostalgia ni para dejar huellas de algún pasado que se idealiza. Al fin y al cabo, las tres novelas muestran los altos niveles de exigencia a las que son sometidos estos sujetos a los que se les aplican desde el comienzo de su existencia las tecnologías tendientes a convertirlos en buenos ciudadanos para llegar a ser alguien en la vida, eso que suele ser definido con el término "crecer", concepto que Stockton se encarga de deconstruir mediante su noción de "crecimiento lateral" (growing sideways). En términos del personaje de Puenzo, "dejar de ser una promesa" (125) es lo que supone llegar a ser real. Esto adquiere un significado terrorífico en los personajes adultos que circulan por ese paisaje. En la novela de Acevedo, porque los pocos adultos que aparecen son percibidos como zombis, más "marcianos" que los extraterrestres. En Puenzo, son dibujados lisa y llanamente como personajes de animación o tomados de las historietas. En Osos, a la madre (la adulta responsable) no solo se la ve extenuada, sino también robotizada: actúa como una marioneta que ha perdido toda autonomía. Las tres novelas muestran el peso de la fantasía y del desvarío como aquello que rescata a las subjetividades frente al riesgo de convertirse en una caricatura grotesca. Como sostiene Jack Halberstam, a quien pertenece la idea de un conocimiento "indisciplinado", el proyecto político debe ser buscado en un lugar intermedio entre la resignación cínica y el optimismo naïve (2011). Las tres novelas buscan dar forma a este impulso. Echan mano a cierto recurso de la estupidización (o "boludización", como señala Francica), que no es ingenuidad, ni abandono de una aproximación inteligente a problemas acuciantes. Es una búsqueda de otra forma de lógica, que se sostenga en la idea de fracaso. Según la definición de Halberstam: "we might read failure, for example, as a refusal of mastery, a critique of the intuitive connections within capitalism between success and profit, and as a counterhegemonic discourse of losing. Stupidity could refer not simply to a lack of knowledge but to the limits of certain forms of knowing and certain ways of inhabiting structures of knowing" (pos. 298). Esa lógica infante, a la que Halberstam define como una "maravillosa anarquía", es una que nos acompaña desde nuestro origen y nunca nos dejó; a la que podemos retornar eventualmente cuando abrimos un libro o apretamos el botón de la tele para asomarnos a determinadas ficciones. Claramente, no es un problema de lo que vemos, sino de cómo lo vemos, como nos señala Halberstam en su defensa de las historias animadas. El pensamiento crítico también se nutre de mucho de lo que ciertas zonas de la producción cultural suelen desdeñar o descartar, en un gesto análogo al de aquellas opiniones adultas que tienden a minorizar a quienes constituyen una amplia franja de humanidad, relegándolas al territorio de lo in-fante, de las subjetividades sin voz o sin capacidad de habla. Como antes se hiciera con los bárbaros, parece que no hay nada nuevo bajo el sol. Y, sin embargo, la narrativa actual está ahí para recordarnos que esas voces son potentes y que se abren paso horadando los sistemas literarios, del mercado o de las producciones culturales a las que ya escuchamos como quien oye llover. 


\section{Bibliografía citada}

Acevedo, I. 2010. Una idea genial. Buenos Aires: Mansalva.

—. 2017. Jajaja. Buenos Aires: Mansalva.

- 2017. Quedate conmigo. Buenos Aires: Marciana.

Carricaburo, Norma. 2008. Del fonógrafo a la red. Literatura y tecnología en la Argentina. Buenos Aires: Ediciones Circeto.

Cosse, Isabella. 2014. Mafalda: historia social y política. Buenos Aires: FCE.

De Leone, Lucía. 2020. "La pampa errante. Un trayecto de desobediencia”. En En la intemperie. Poéticas de la fragilidad y la revuelta coordinado por Laura A. Arnés, Lucía De Leone, María José Punte, Tomo V de la Historia Feminista de la Literatura Argentina, dirigida por Laura A. Arnés, Nora Domínguez y María José Punte, 187-216. Villa María: Eduvim.

Donoso Pinto, Catalina. 2020. No somos niños. Representaciones problemáticas de la infancia. UAH ediciones (Universidad Alberto Hurtado): Santiago de Chile. Kindle.

Feinmann, José Pablo. 2000. "Marcianos". Pasiones de celuloide. Ensayos y variedades sobre cine, 21-32. Buenos Aires: Norma.

Foucault, Michel. 2010. Los anormales. Trad. Horacio Pons. Buenos Aires: FCE.

Francica, Cynthia. 2015. "Lo 'queer infantil' en la literatura de Belleza y Felicidad. Temporalidad, crisis y política”. En Cecilia Macón y Mariela Solana (eds.), 157183. Pretérito indefinido: afectos y emociones en las aproximaciones al pasado. Buenos Aires: Título.

Hadad, Camila. 2017. "Inés Acevedo: Me gusta escribir hasta la lista de compras". Infobae/Cultura, 10 de agosto de 2017.

https://www.infobae.com/cultura/2017/08/10/ines-acevedo-me-gusta-escribirhasta-la-lista-de-las-compras/

Halberstam, J. 2011. The Queer Art of Failure. Durham and London: Duke University Press. Kindle.

Lerer, Seth. 2008. Children's Literature. A reader's History, from Aesop to Harry Potter. Chicago and London: Chicago University Press.

Lobato, Mirta Zaida. 2019. Infancias argentinas. Buenos Aires: Edhasa.

Puenzo, Lucía. 2007. La maldición de Jacinta Pichimahuida. Buenos Aires: Interzona.

Punte, María José. 2018. Topografías del estallido. Figuras de infancia en la literatura argentina. Buenos Aires: Corregidor. 
Schérer, René y Guy Hocquenghem. 1979 [1976]. Co-ire. Albúm sistemático de la infancia. Barcelona: Editorial Anagrama.

Stockton, Kathryn B. 2004. "Growing Sideways, or Versions of the Queer Child: The Ghost, the Homosexual, the Freudian, the Innocent, and the Interval of the Animal". En Curiouser. On the queerness of children, editado por Steven Bruhm and Natasha Hurley, 277-311. Minneapolis: University of Minnesota Press.

Stockton, Kathryn B. 2009. The Queer Child. Or Growing Sideways in the Twentieth Century. Durham and London: Duke University Press.

Vecchio, Diego. 2010. Osos. Rosario: Beatriz Viterbo.

Zipes, Jack. 2012. The Irresistible Fairy Tale. The Cultural and Social History of a Genre. Princeton: Princeton University Press. Kindle. 